\title{
17 Dynamics of Soil Salinity in Denmark
}

\author{
Laurids Siig Christensen
}

\section{CONTENTS}

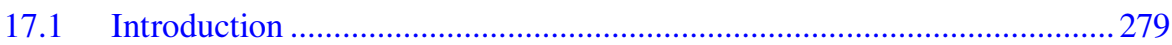

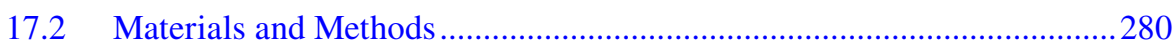

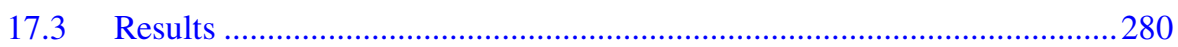

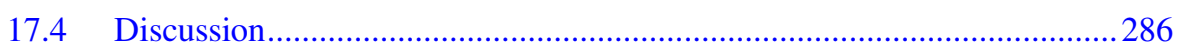

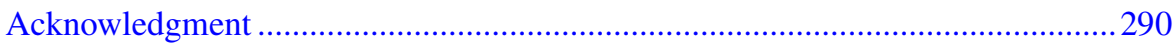

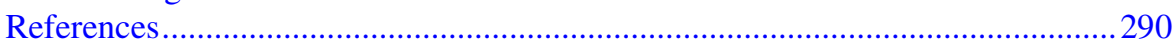

\subsection{INTRODUCTION}

Denmark is a nation of islands, generally with a low altitude, less than $200 \mathrm{~m}$ above sea level. The landscape is rich in marshland and meadows, and arable land constitutes $62 \%$ of the country (Christensen 2019). Because of its geography and because agriculture and food production in Denmark play a prominent economic role, Denmark is among the countries in the world that are expected to have to pay the highest costs of accommodating to climate changes. Denmark is also a relatively small country of $42,900 \mathrm{~km}^{2}$ with an exceptionally long coastline of $7,300 \mathrm{~km}$. No spot is more than $50 \mathrm{~km}$ from the sea, and the country is located between a brackish sea, the Baltic Sea, and the saline North Sea. This means that coastal areas in Denmark are exposed to sea salinities ranging from approximately $0.6 \%$ (wt/vol) on the island of Bornholm to $3.2 \%$ (wt/vol) on the North Sea coast of Jutland and the Danish islands of the Wadden Sea. The combination of the national importance of food production and this gradient of salt in the sea surrounding Danish islands also means that Denmark, among European countries, has optimal conditions for experimenting with halo-tolerant and halophilic plant production under various conditions in order to develop a contingency in food production against climate changes.

The state of salinity in soil on a national scale in Denmark is not known, nor have the dynamics of soil salinity and the mechanisms affecting this on a national scale been subject to research in Denmark. During the present study, an approach was established of sampling soil and water sources and measuring electrical conductivity (EC) in soil of highly variable nature, as well as in various water sources. Baselines of conductivity were defined in soil, as well as in water streams, as distant from the sea as possible in Denmark. In addition, coastal landscapes were chosen for monitoring because of records of flooding from the sea or because of other indications of salinity. A special focus was on smaller islands in Denmark, since on these islands, farming, in many cases, is practiced close to the sea. 


\subsection{MATERIALS AND METHODS}

Top-soil samples of 15-30 grams were collected with a cylindrical soil spear sampling device to a depth of $30 \mathrm{~cm}$. In some cases, surface soil (named as such in Table 17.1) samples were collected by scraping the soil surface with a spoon. Soil samples were dried for $>8$ hours in an incubator at $35-40^{\circ} \mathrm{C}$. The soil samples were sieved through a mesh of $2 \mathrm{~mm}$, and a total of 15 grams was diluted with 5 parts (wt/wt) of demineralized water and left for $>1$ hour. Finally, the samples were centrifuged at 2,850 g for 5 minutes in a Rotofix 32A Centrifuge. Water samples were collected in $50 \mathrm{~mL}$ PP tubes.

Prior to measurement, samples were incubated in a water bath at $25^{\circ} \mathrm{C}$ until a sample temperature of $20-25^{\circ} \mathrm{C}$ was reached. The EC was measured with a Thermo Scientific $^{\mathrm{TM}}$ Orion Star ${ }^{\mathrm{TM}}$ A122 Conductivity Portable Meter. For soil samples, the conductivity measured, referred to as $\mathrm{EC}_{1: 1}$, was multiplied by the dilution factor ( 5 as a standard). Conductivity was measured $>3$ times in every sample and a mean value estimated.

A total of $>140$ top-soil samples and $>120$ water samples originating from streams, drainpipes, lakes, wells, etc. were collected in Denmark and analyzed. Locations of sampling were widely dispersed to get an overview, on a national scale, of variation in soil salinity. Multiple samples were collected from central regions of Jutland and Zealand, as well as on every island studied, to estimate a baseline soil conductivity in areas where the effects of the sea were expected to be minimal. Other locations, expected to be affected by the sea, were chosen, from which multiple samples were collected in order to increase the reliability of measurements and possibly reveal dynamics in variation of soil salinity. Samples were predominantly collected in March in both years in order to minimize the impacts on EC of fertilizer added by farmers and the effects of increased biological activity in the root zone.

\subsection{RESULTS}

A map of Denmark, Figure 17.1, shows three regions of Jutland and two islands in the northern Baltic Sea (Kattegat) where soil salinity was expected to be affected by the sea or by inlet seas. In addition to these areas, samples were collected from the Wadden Sea marsh in the south-west region of Jutland and from North Sea coastal areas north of the Wadden Sea marsh. The Varde River drains a considerable part of South-West Jutland and is the only river in Denmark that leads into the Wadden Sea via Ho Bay, without a sluice to regulate water level and flood. The river valley is subject to flooding by the North Sea almost every winter season. The Skjern River is the water-richest river in Denmark, draining an even larger area in Mid-West Jutland. It leads into Ringkoebing Fjord, which is regulated by a sluice to the North Sea. The fjord, Limfjorden, in northern Jutland, is open without sluices to the sea on both "sides" of Jutland and is subject to a considerable influx of water from the North Sea. Limfjorden is incidentally flooding arable land. Laesoe is an island, where a major marsh area (Rønnerne) is frequently flooded by the sea. Due to the combination of flooding in the winter season, a water-impermeable sub-terrain soil layer at a depth of 1-2 $\mathrm{m}$ at "Rønnerne" and evaporation of flooded water during the summer season, 


\section{TABLE 17.1}

\section{Electrical Conductivity Measured in Soil Samples}

\section{Sample Collection}

Baseline soil, central Jutland, 2019

Baseline soil, central Jutland, 2020

Baseline soil, central Zealand, 2019

Baseline soil, central Zealand, 2020

Soil of uncultivated forest, Allindelille Fredsskov, 2020

Sejeroe locations

Soil of central island, baseline, 2020

Soil of rape field subject to spray from waves, 2019*

Wheat affected by sea spray, line 1, $25 \mathrm{~m}$ off coast, 2020

Wheat affected by sea spray, line 1,75 m off coast, 2020

Wheat affected by sea spray, line 1, $150 \mathrm{~m}$ off coast, 2020

Wheat affected by sea spray, line 2, $25 \mathrm{~m}$ off coast, 2020

Wheat affected by sea spray, line 2, $75 \mathrm{~m}$ off coast, 2020

Wheat affected by sea spray, line $2,150 \mathrm{~m}$ off coast, 2020

\section{Laesoe locations}

Soil of central island, baseline, 2019

Rønnerne, soil above line of flood, 2020

Rønnerne, flooded marsh (area of salt production), 2020

Soil of flooded arable land, 2020

\section{Other islands}

Fur, soil of high meadow, 2019

Fur, soil of low meadow, 2019 (record of flood)

Mors, soil of plowed field, 2020

Areas near Limfjorden

Sandy soil not flooded by the sea, 2020

Soil of meadow not flooded by the sea, 2020

Soil of flooded meadows, 2020

Areas near Ringkøbing Fjord

Soil baseline, 2019

Soil of plowed field, 2020

\section{Areas near the North Sea coast}

Soil samples collected 3-10 km off North Sea coast, 2019

Soil samples collected 3-10 km off North Sea coast, 2020

\section{Varde Å (river) meadow}

River valley, $1 \mathrm{~km}$ from outlet to the Wadden Sea, 2020

River valley, $3 \mathrm{~km}$ from outlet to the Wadden Sea, 2020

River valley, $5 \mathrm{~km}$ from outlet to the Wadden Sea, 2020

River valey, $8 \mathrm{~km}$ from outlet to the Wadden Sea, 2020

\section{The Wadden Sea marsh}

Tønder area, 2019

\begin{tabular}{|c|c|c|c|}
\hline $\begin{array}{l}\text { Sample } \\
\text { Size }\end{array}$ & $\begin{array}{c}\text { Range of } \\
\mathrm{EC}_{1: 1} \mathrm{mS} / \mathrm{cm}\end{array}$ & $\begin{array}{c}\text { Mean } \\
\mathrm{EC}_{1: 1} \mathrm{mS} / \mathrm{cm}\end{array}$ & SD \\
\hline 8 & $0.11-0.75$ & 0.38 & 0.21 \\
\hline 5 & $0.07-0.28$ & 0.15 & 0.07 \\
\hline 5 & $0.49-0.67$ & 0.57 & 0.05 \\
\hline 7 & $0.16-0.31$ & 0.27 & 0.08 \\
\hline 4 & $0.4-0.9$ & 0.72 & 0.2 \\
\hline 6 & $0.2-0.49$ & 0.29 & 0.06 \\
\hline 5 & $0.6-1.24$ & 0.96 & 0.23 \\
\hline 1 & & 0.79 & \\
\hline 1 & & 0.51 & \\
\hline 1 & & 0.35 & \\
\hline 1 & & 0.48 & \\
\hline 1 & & 0.44 & \\
\hline 1 & & 0.33 & \\
\hline 9 & $0.26-0.81$ & 0.56 & 0.2 \\
\hline 1 & & 1.07 & \\
\hline 1 & & 4.96 & \\
\hline 2 & $1.47-1.78$ & 1.63 & 0.15 \\
\hline 1 & & 0.71 & \\
\hline 1 & & 1.34 & \\
\hline 1 & & 0.28 & \\
\hline 3 & $0.11-0.32$ & 0.24 & 0.06 \\
\hline 1 & & 0.4 & \\
\hline 3 & $1.87-7.15$ & 3.87 & 2.35 \\
\hline 5 & $0.52-0.92$ & 0.71 & 0.15 \\
\hline 1 & & 0.11 & \\
\hline 3 & $1.2-2.8$ & 1.79 & 0.7 \\
\hline 3 & $0.14-0.41$ & 0.29 & 0.11 \\
\hline 3 & $2.33-5.3$ & 3.66 & 1.76 \\
\hline 2 & $2.28-2.96$ & 2.62 & 0.34 \\
\hline 1 & & 0.5 & \\
\hline 1 & & 0.61 & \\
\hline 4 & $0.93-1.28$ & 1.03 & 0.07 \\
\hline
\end{tabular}

*See Figure 17.2. 


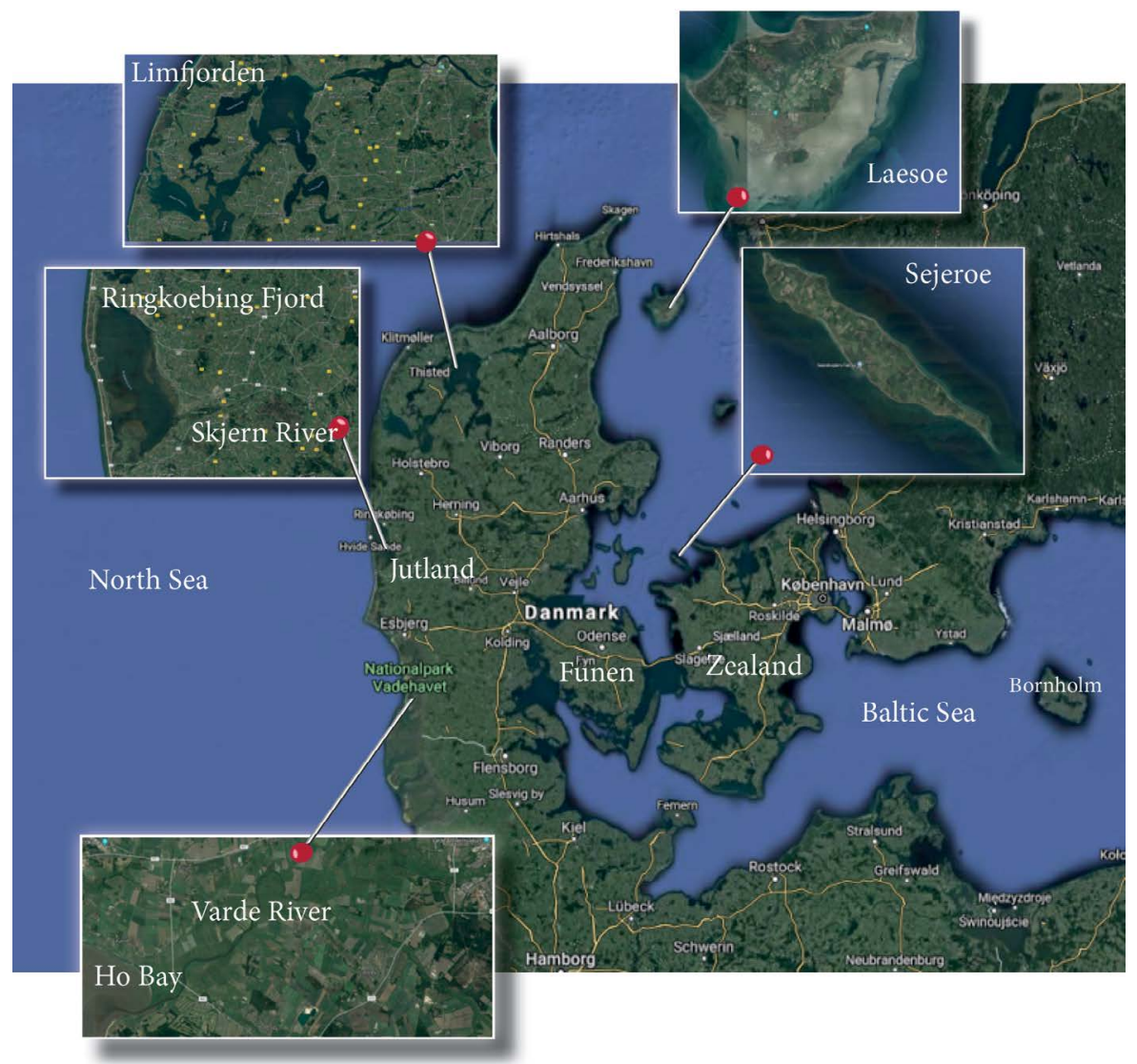

FIGURE 17.1 Map of Denmark showing five locations, potentially affected by marine salt, where multiple soil and water samples were collected.

salinity in wells may increase up to $17 \%$ (wt/vol) (Jørgensen 2002). These wells during the 12th-16th century AD served as substrate for a production of salt flakes, a production now re-established for archeological research (Laesoe salt). Sejeroe is an island $<2 \mathrm{~km}$ wide without flooding during the past 70 years. The central axis of the island was covered by a glacier during the latest Ice Age and is now flanked by moraine hills toward the coast. The central axis of the island was sea floor, until the land was elevated approximately 6000 years ago.

Data on measurements of EC in soil and in water samples are compiled in Table 17.1 and Table 17.2, respectively. These tables do not include all data collected during the present study, but are representative of the sample collections and allow conclusions on causal relationships to be suggested. Other data comply with these causal relationships, but do not offer anything substantial that can be added to these conclusions.

Table 17.1 shows data on soil samples. Samples were stratified in order to define, tentatively, baseline values in soil in central areas of Jutland and Zealand, respectively, 


\section{TABLE 17.2}

\section{Electrical Conductivity Measured in Water Samples}

\section{Sample Collection}

Baseline water streams**, central Jutland, 2020

Baseline water streams, central Zealand, 2020

Baseline lakes and ponds, central Zealand, 2020

Rain puddles, central Jutland \& central Zealand, 2020

Ponds of uncultivated forest, Allindelille Fredsskov, 2020

\section{Sejeroe locations}

Rain puddles on well-drained cultivated land, 2020

Rain puddles on pasture not drained, nor cultivated, 2020

Creek/Canal water (effluent of drain pipes), 2020

Sub terrain $(60 \mathrm{~cm})$ water at Horsekaer, 2019

Well at Horsekaer, 2019

Lakes and ponds, 2020

\section{Laesoe locations}

Creek/canal water, 2020

Puddle of remains of flood, 2020

\section{Other islands}

Fur, drain canal, 2019

Mors, drain creek, 2020

Areas near Limfjorden

Influx sources to Limfjorden, 2020

\section{Areas near Ringkøbing Fjord}

Influx sources to Ringkøbing Fjord, 2019

Influx sources to Ringkøbing Fjord, 2020

Ringkøbing Fjord, 2019

Ringkøbing Fjord, 2020

\section{Areas near the North Sea Coast}

Henne Mølleå, 2019

Varde Å (river) meadow

Influx sources to Ho Bay, 2020

The Waddensea marsh

Water of canal, 2019

$\begin{array}{cccc}\begin{array}{c}\text { Sample } \\ \text { Size }\end{array} & \begin{array}{c}\text { Range of } \\ \mathrm{EC}_{\mathbf{w}} \mathbf{m S} / \mathbf{c m}\end{array} & \begin{array}{c}\text { Mean } \mathbf{E C}_{\mathbf{w}} \\ \mathbf{m S} / \mathbf{c m}\end{array} & \begin{array}{c}\text { SD } \\ 3\end{array} \\ 0.45-0.51 & 0.48 & 0.03 \\ 8 & 0.54-0.65 & 0.62 & 0.05 \\ 5 & 0.31-0.62 & 0.5 & 0.11 \\ 8 & 0.15-0.64 & 0.41 & 0.19 \\ 5 & 0.2-0.75 & 0.55 & 0.2 \\ & & & \\ 7 & 0.27-0.62 & 0.45 & 0.12 \\ 8 & 0.83-1.34 & 1.02 & 0.14 \\ 3 & 1.64-1.85 & 1.71 & 0.1 \\ 1 & & 2.23 & \\ 1 & & 1.89 & \\ 3 & 0.95-2.02 & 1.32 & 0.75 \\ & & & \end{array}$

7

$\begin{array}{lll}0.27-0.62 & 0.45 & 0.12 \\ 0.83-1.34 & 1.02 & 0.14 \\ 1.64-1.85 & 1.71 & 0.1 \\ & 2.23 & \\ & 1.89 & \\ 0.95-2.02 & 1.32 & 0.75 \\ & & \\ 0.21-0.84 & 0.52 & 0.32 \\ & 47.2 & \end{array}$

suggested to be less affected by the sea than coastal areas. The samples showed little variation, as estimated by Standard Deviation (SD), within each of the sample collections. However, baseline $\mathrm{EC}_{1: 1}$ values in soil were significantly lower in Jutland than in Zealand in both years. In addition, in Jutland as well as in Zealand, baseline values were significantly lower in 2020 than in 2019, respectively. Samples from soil in the uncultivated forest (Allindelille Fredsskov), located in central Zealand, represent the variation in a unique ecosystem of forest, meadow, and ponds, known to be 
untouched by man for many centuries and without any drainage systems. EC in soil of this ecosystem was found to be significantly higher than outside the ecosystem in the same region and the same time of sampling (March 2020).

From locations where soil salinity is expected to be affected by the sea, most samples were collected on the two islands Sejeroe and Laesoe, both located in Kattegat with sea salinity expected to vary within a range of $2.0-2.6 \% \mathrm{wt} / \mathrm{vol}$. In both cases, a tentative baseline soil salinity was defined in central regions of the island. The baseline soil $\mathrm{EC}_{1: 1}$ value was significantly higher on Laesoe in 2019, than on Sejeroe in 2020. However, this difference might reflect differences in precipitation between the two years (shown in Figure 17.2), rather than any difference related to location or geology of the two islands. It is a paradox that Laesoe, although renowned as the "island of salt" due to salt flake production on Rønnerne, has a salinity in the root zone of the sandy top-soil comparable to baseline values in other parts of Denmark.

On the south-west-oriented coast of Sejeroe, a significant effect was observed in a rape field, presumably due to saline spray caused by waves from two storms in late November and early December 2018 (Figure 17.3). Soil samples were collected from this field in March 2019 and an increase in top-soil salinity depending on distance to the coast and apparently correlating with rape growth performance was observed as shown (Figure 17.2). A similar effect, consistent with saline spray from recent storms, was observed in a wheat field on Sejeroe in early 2020. In order to establish an effect depending on distance to the coast, samples were collected in two lines in the field, and a decrease in $\mathrm{EC}_{1: 1}$ value with distance from the coast was observed

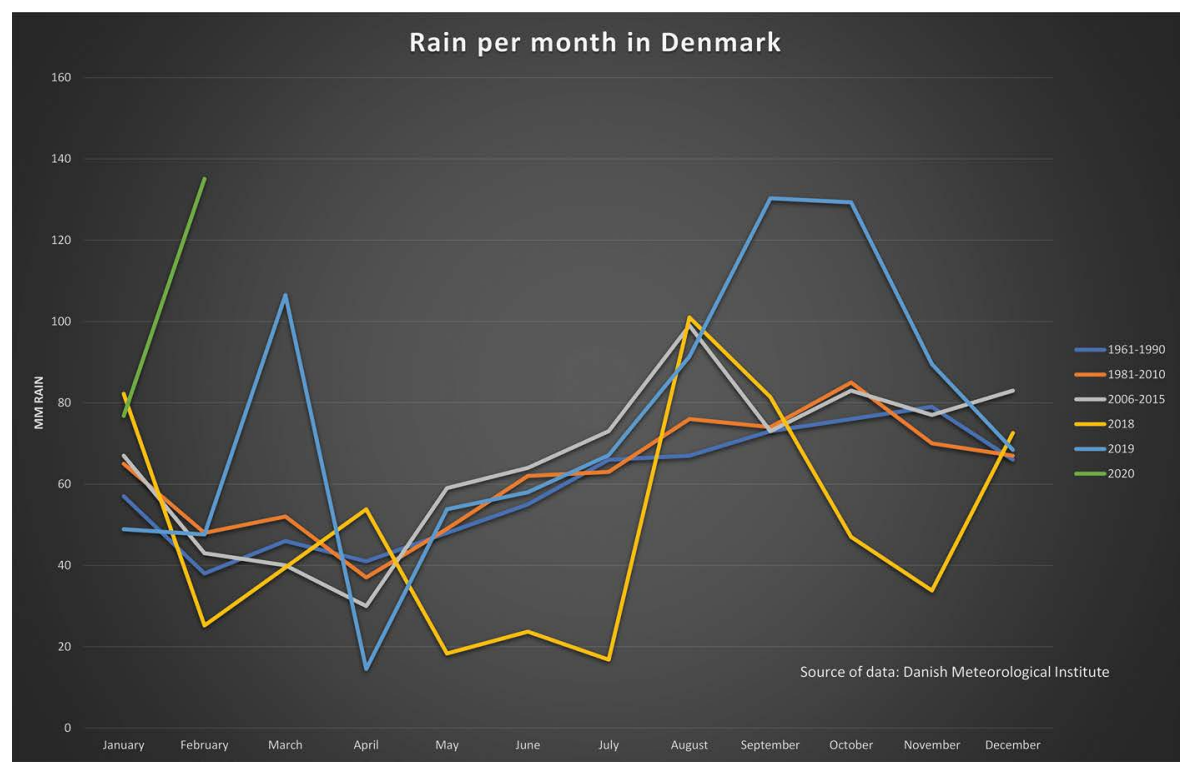

FIGURE 17.2 Precipitation of rain per month in Denmark. Mean values of rain are shown for three reference periods, 1961-1990, 1981-2010 and 2006-2016, In addition, precipitation of rain per month is shown for 2018, 2019 as well as for January and February 2020. 


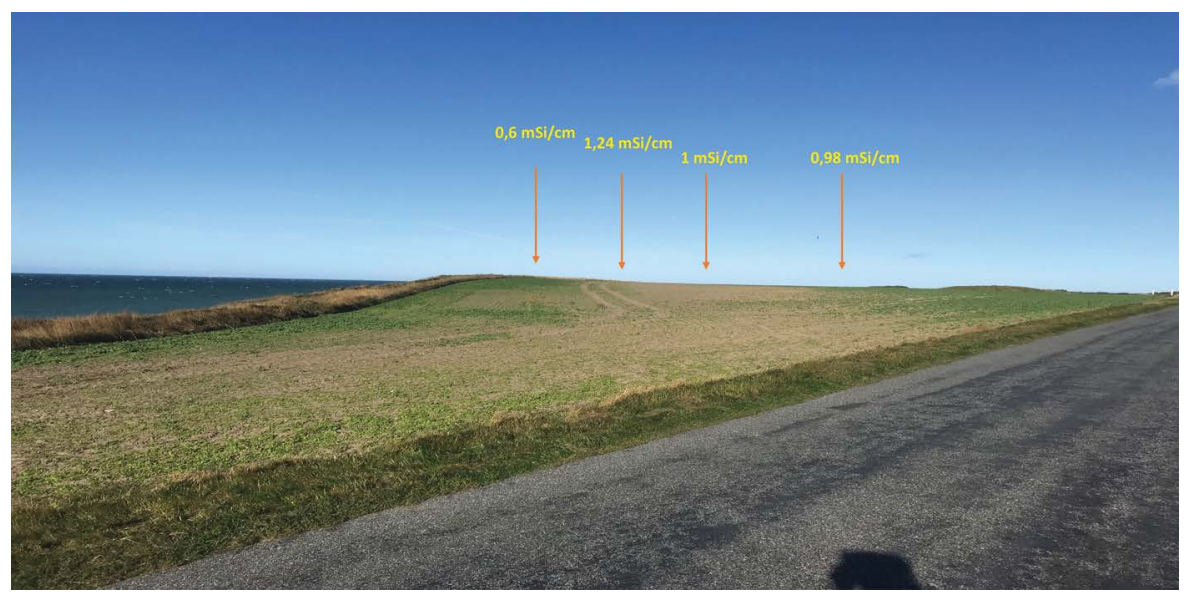

FIGURE 17.3 Rape field on the south-west oriented coast of the island of Sejeroe affected by saline spray from waves breaking on the beach.

in both lines. These values were all higher than baseline values during the same sampling period.

Laesoe is one of several islands that experienced flooding from the sea during the winter of 2019-20. Elevated values of $\mathrm{EC}_{1: 1}$ were observed in soil samples from flooded areas, while soil samples above the line of flood did not exhibit a significantly increased $\mathrm{EC}_{1: 1}$ value.

Results of $\mathrm{EC}_{1: 1}$ measures in samples from the islands of Fur and Mors are also shown in Table 17.1. The islands are both located in the western part of Limfjorden, and Fur has a record of incidental flooding of arable land. A significant difference in $\mathrm{EC}_{1: 1}$ in top-soil is seen between non-flooded meadow and land with a record of flooding on Fur, while $\mathrm{EC}_{1: 1}$ of soil samples on the island of Mors were within the national baseline levels (data not shown).

Soil samples from areas east of Ringkoebing Fjord in 2019 revealed slightly elevated values of salinity, while soil samples collected in 2020 did not indicate elevated values of $\mathrm{EC}_{1: 1}$ when compared to national baseline levels for 2019 and 2020, respectively. Soil samples collected near the North Sea coast in both 2019 and 2020 revealed higher $\mathrm{EC}_{1: 1}$ values than baseline soil in Jutland in 2019 and 2020, respectively.

Soil samples from the Varde River Valley - flooded almost every year and repeatedly flooded by the Wadden Sea in the winter of 2019-20 - showed significantly increased $\mathrm{EC}_{1: 1}$ values near the gate, Ho Bay, to the Wadden Sea. These levels decreased to values only slightly higher than national baseline levels at distances of $>5 \mathrm{~km}$ from Ho Bay.

The marshland of the Danish Wadden Sea revealed slightly elevated levels of soil salinity compared to baseline values.

Table 17.2 shows representative data on water samples. Unfortunately, few water sample data were collected in 2019, and comparison of baseline $\mathrm{EC}_{\mathrm{w}}$ values between 2019 and 2020 is not possible. However, as in the soil samples, baseline $\mathrm{EC}_{\mathrm{w}}$ values in water streams were lower in Jutland than in Zealand. 
$\mathrm{EC}_{\mathrm{w}}$ values in terrestrial sources of water for Limfjorden are higher than in terrestrial sources of water for Ringkoebing Fjord and Ho Bay. Ringkoebing Fjord water exhibited a significantly higher $\mathrm{EC}_{\mathrm{w}}$ in 2019 than in 2020.

EC in samples from ponds in the uncultivated forest (Allindelille Fredsskov) was within baseline values of central Zealand and these are suggested to be due to soluble components of microbial activity and oxidative and other forms of degradation of a relatively rich source of biological material.

On Sejeroe, significant differences were observed in $\mathrm{EC}_{\mathrm{w}}$ values in puddles of rainwater depending on conditions of draining and cultivation of the location. Higher $\mathrm{EC}_{\mathrm{w}}$ values were observed in puddles on land not drained, nor recently cultivated. Water samples from effluent of drainpipes, wells, lakes, and ponds, as well as in water $60 \mathrm{~cm}$ sub-terrain on Sejeroe, showed significantly higher values of $\mathrm{EC}_{\mathrm{w}}$ than baseline values in central Zealand and central Jutland. On Laesoe, creeks and canals of drain effluent from central parts of the island do not exhibit $\mathrm{EC}_{\mathrm{w}}$ values significantly above baseline values. A puddle of remains from the floods reveals the salinity of seawater affecting the soil salinity in such areas of flooding on this island. Results of $\mathrm{EC}_{\mathrm{w}}$ values in water samples from the islands of Fur and Mors are also shown (Table 17.2). On both islands, $\mathrm{EC}_{\mathrm{w}}$ values in drain effluent, significantly above baseline values, indicate reservoirs of higher salinity in deeper layers of soil. Values of $\mathrm{EC}_{\mathrm{w}}$ in water streams leading to Ringkoebing Fjord were below baseline values and, hence, did not indicate any reservoirs of salinity in deeper layers of soil in this area. $\mathrm{EC}_{\mathrm{w}}$ values in terrestrial sources of water leading to Ho Bay (Table 17.2) also did not indicate reservoirs of higher salinity in any soil layers east of the study locations in the Varde River Valley. The $\mathrm{EC}_{\mathrm{w}}$ value, significantly above baseline $\mathrm{EC}_{\mathrm{w}}$ values, found in canal water of the Wadden Sea marsh revealed sources of layers of soil with salinity significantly above baseline values.

\subsection{DISCUSSION}

The present study has been the first attempt to map soil salinity and parameters affecting the dynamics of soil salinity in Denmark. Defining a methodological approach to estimate soil salinity was the first obstacle - accentuated by the finding of only low to moderate salinity levels in soil and terrestrial water sources during the study period. Measurements of EC in pore water of the root zone soil is a standard procedure for a cost-efficient and rapid estimation of soil salinity potentially affecting the growth performance of cultured plants. It was found to be also an extremely sensitive analysis. $\mathrm{NaCl}$ is the salt of primary concern when addressing a problem of increased salinity in the North Sea region due to climate changes. However, it should also be stressed that other salts such as those in fertilizers, as well as charged components of soil resulting from microbial activity or oxidative and other forms of degradation of biological material, will contribute to the EC of a soil sample. This was illustrated by the $\mathrm{EC}_{1: 1}$ measurements of soil samples collected in the ecosystem reservation Allindelille Fredsskov, revealing a variation and values of $\mathrm{EC}_{1: 1}$ higher than those observed in arable land in the same central region of Zealand and same period of sampling. Rock salt is not present in Denmark and salt plugs originating from ancient seas are - when present - at a depth of more than $300 \mathrm{~m}$. 
A variety of sampling and sample processing procedures already exists (e.g. De Vos 2018), but common to most of them is that they are suitable to study variation over time of salinity on one location and in one type of soil. Mapping salinity on a national scale involves the analysis of a large variety of soil types and, hence, a more complex sampling and sample processing to make results comparable is needed. And even then, storage under ambient conditions in some samples revealed significant differences when analyzed one year later, probably as a result of microbial activity and the degradation of organic material. The sampling and sample processing steps prior to EC measurement adopted during the present study will be validated and published elsewhere. However, to overcome variation in $\mathrm{EC}_{1: 1}$ values as a result of sampling and sample processing procedures in soils of great variability it is recommended that a network of sampling sites be developed to be sampled repeatedly in the area studied. During the present study period, the number of sampling sites in Denmark were expanded continuously and as many sites as possible were tested in both years of testing. In those cases, variation in results confirmed the causal relationships of dynamics in salinity suggested here. In other cases, the lack of repetition in sampling in terms of suggesting causal relationships were evident. For instance, the lower baseline soil salinity observed on the island of Sejeroe in 2020 compared to baseline soil salinity on the island of Laesoe in 2019 and, likewise, the higher $\mathrm{EC}_{1: 1}$ values found 3-10 km off the North Sea coast in 2019, compared to those in the same area in 2020, are suggested not to reflect differences in geology or marine impacts on these locations. Instead, they are most likely due to differences in precipitation of rain between the two winters in combination with the low ionic retention ability of the sandy soil on the two islands and in West Jutland.

Combining top-soil sampling with sampling of water sources was found useful in trying to reveal the dynamics of soil salinity in Denmark. Since there is no given proportion between drain water volume and pore volume of the soil drained, values of EC of the two sources are not inter-comparable, and baseline values should be tentatively defined for both water sources and soil samples, respectively, to allow intra-comparisons. Doing so, water samples with significantly higher $\mathrm{EC}_{\mathrm{w}}$ than baseline values are suggested as a useful source to screen for presence of salt deposits in larger areas of land and in sub-terrain layers of soil. Likewise, $\mathrm{EC}_{\mathrm{w}}$ values significantly below baseline values as well as annual or seasonal variation of these values might reflect the wash-out of salt in sub-surface layers of the basins of West Jutland possibly depending on the annual and seasonal variation of precipitation. Monitoring in years to come will reveal if these suggestions are valid.

Soil salinization is not a new phenomenon, but one which has led to the disintegration of ancient civilizations, e.g. in Mesopotamia, as reviewed by Shahid et al. (2018). Sources of soil salinization are manifold on a global scale as reviewed by Manca et al. (2015), Daliakopoulos et al. (2016), and most recently by De Waegemaeker (2019) for the North Sea Region. Some of these sources are anthropogenic, such as sea-level rise related to climate changes (in part due to human activity), irrigation in some arid regions of the world, and intrusion of seawater in sub-terrain soil layers due to increased use of groundwater for drinking, irrigation and production processes in our part of the world. Others are natural and seasonally variable such as caused by (1) flooding by the sea, (2) spray from waves on the coast, (3) the deposition of 
aerosols from the sea, (4) seawater intrusion by seepage into coastal areas, and (5) capillary transportation of water from deeper layers to the root zone, as well as the counteracting effects of (6) rain. In the present study, we focused on the effects subject to seasonal variation. We saw examples of the impact of all these effects.

The locations chosen for this initial study on dynamics of soil salinity in Denmark represent the major geologies found in Denmark: (1) the moraine landscapes of central Jutland and Zealand, (2) the coastal areas of the major peninsula of Jutland, (3) the small islands, (4) the basin of Mid-West and South-West Jutland, and (5) the Wadden Sea marsh. Each location in Denmark, such as an island, has its own dynamic of soil salinization and may warrant many samples being collected at various locations and times of sampling. Doing this and understanding in depth the dynamics at any location in Denmark is beyond the scope of the present study.

No evidence of accumulation and deposition of salt in Danish soil was seen in our study. This suggests continuous downward transportation of salt from upper layers of soil due to the fact, that precipitation of rain exceeds evapotranspiration under our climatic conditions. Our data suggest that precipitation of rain in relation to time of sampling has a most prominent impact on top-soilEC. Mean values of rain per month (Danish Meteorological Institute) are shown in Figure 17.3 for three reference periods, 1961-1990, 1981-2010, 2006-2015, and for every month since January 2018. Mean values of annual rain for the three reference periods are increasing rapidly in Denmark from $712 \mathrm{~mm}$ during the period of 1961-1990 over $746 \mathrm{~mm}$ during 1981-2010 to $792 \mathrm{~mm}$ during the period of 2006-2015 - an increase of $11 \%$ in average annual precipitation during a period of 60 years. In addition, seasonal and annual variation in meteorological conditions seem to be increasing as well, with extremes in weather conditions being experienced more frequently. The year 2018 was characterized by a very low annual precipitation of $595 \mathrm{~mm}$ and a serious drought starting May 2018. The year 2019, on the other hand, was characterized by a very high annual precipitation of $905 \mathrm{~mm}$. In particular, the winter season of 2019/20 (September 2019-February 2020) had an extremely high precipitation of $629 \mathrm{~mm}$ rain. The sampling in spring 2019 took place immediately after a peak precipitation in March, which assumably would reduce $\mathrm{EC}_{1: 1}$ values found at that time, but the extreme amount of rain during the winter of 2019-20 is reflected in the significant and consistently lower baseline values found in 2020 compared to those of 2019.

Denmark's landscape is without visible bedrock - except on the island of Bornholm in the Baltic Sea. It is resting on a pillow of chalk from ancient marine deposits. Geologically, Denmark can be divided into two parts due to the glaciers of the latest Ice Age stopping along the longitudinal central axis of Jutland. Thus, the land in Mid- and South-Jutland west of the longitudinal axis was a basin of water streaming from melting glaciers, while Northern Jutland, Funen, and Zealand are rich in moraine landscapes. The soil of Mid- and South-West Jutland has a high content of sand and gravel, while soil in the rest of the country is more variable and often has a higher content of clay. This is reflected in higher mean baseline EC values of soil and drain water on central Zealand compared to those of central Jutland, suggested to be due to the higher ionic retention ability of clay compared to that of sand. The soil, rich in sand and gravel, of the basin of Mid- and South-West Jutland also has good vertical drainage capacity, and this is reflected in the invariably low $\mathrm{EC}_{\mathrm{w}}$ 
values in terrestrial streams of water leading to Ringkoebing Fjord and the Wadden Sea via Ho Bay, respectively, compared to those of water streams in the rest of the country (Table 17.2). The $\mathrm{EC}_{\mathrm{w}}$ values significantly higher than baseline values found in drain water in the Wadden Sea marsh and on islands not flooded (Table 17.2) are suggested to reflect seepage of seawater into these coastal areas. This suggestion is consistent with experiences in the past 70 years, that an increase in use of freshwater reservoirs for drinking or other purposes often leads to an increase in salinity in these reservoirs.

Airborne transmission of marine salt has been generally ignored in the North Sea region although acknowledged as the major source of soil salinity in other parts of the world such as the coastal perimeter of Australia (Hingston and Gailitis 1976). This discrepancy may be due to differences in the ratio of precipitation of rain and evapotranspiration. Yet, through epidemiological research comprehensive experience has been established on long-distance airborne transmission of infectious animal diseases in Denmark (Christensen et al. 1993, Christensen et al. 2005) and it is suggested that an airborne contribution to soil salinity in the North Sea region should not be ignored. Transport of salt in marine aerosols is also revealed by the salt deposited on windows and windscreens of cars in coastal areas subject to the mist of the North Sea. Transportation of salt by spray created by waves breaking on the coast was clearly demonstrated during the present study on the island of Sejeroe (Table 17.1), but this phenomenon is expected to be relevant for only a few hundred meters from the coast. Transportation of salt by aerosols developed at sea and selected for by their buoyant density and ability to float on ascending warm air, on the other hand, might take place over several hundred kilometers. Top-soil samples collected 3-10 km off the North Sea coast both in 2019 and in 2020 (Table 17.1) revealing higher EC values than baseline values found in Jutland in 2019 and 2020, respectively (Table 17.1), is suggested to reflect aerosol transmission of salt from the sea.

In both winters of 2018/19 and 2019/20 extensive flooding of arable land was seen in Denmark. In the winter of 2019/20, the effects were significantly counteracted by an extreme precipitation of rain. The impact of this precipitation of rain was seen in the variation of $\mathrm{EC}_{\mathrm{w}}$ values of Ringkoebing Fjord. The regulation of the water level by a sluice towards the North Sea occasionally allows influx of seawater resulting in brackish water of the fjord. However, the extreme supply from terrestrial water sources in 2020 resulted in a drop in $\mathrm{EC}_{\mathrm{w}}$ values in the fjord from $5.02 \mathrm{mS} / \mathrm{cm}$ in 2019 to $1.93 \mathrm{mS} / \mathrm{cm}$ in 2020 (Table 17.2). The balance between impacts of flood versus precipitation is also seen in the Varde River Valley in 2020. A significant drop in $\mathrm{EC}_{1: 1}$ values in soil samples over a few kilometers distance to the river outlet to Ho Bay is suggested to reflect the locations of the interface between effluent terrestrial water and influx of North Sea water during that particular flooding period. The location of this interface is expected to vary from year to year due to an annual balance between rain and flooding by the North Sea.

The EC values found during the present study do not indicate any presence of high soil salinity in Denmark - suggested to be due to a prevailing impact of high precipitation of rain as observed, in particular, during the winter of 2019/20. Due to the high precipitation of rain and the nature of soil in Denmark, elevated salinity in the root zone 
caused by any mechanism of supply of salt is expected to be of a temporary nature. Yet, increased salinity in soil compared to baseline values in Denmark was found. Coastal areas and some smaller islands have moderate salinity levels in sub-terrain soil layers, suggested to be due to seepage from the coast. This sub-terrain salinity could possibly affect growth of plants in very dry seasons due to upward capillary transportation from deeper layers of saline water. Also, farmers do report that the flooding of arable land is seen with increasing frequency in Denmark, in particular on the smaller islands. Experiences from such incidences - yet in an anecdotal form - suggest that the impact on performance of conventional agriculture is evident and only reverts to former performance over a period of several years (5-7 years have been mentioned by farmers). This may be due not only to an increased salinity in the root zone, but also due to waterlogging increasing the uptake of $\mathrm{Na}^{+}$and $\mathrm{Cl}^{-}$and decreasing the uptake of $\mathrm{K}^{+}$into plant shoots (Barrett-Lennard 2003, Barrett-Lennard and Shabala 2013).

Thus, with extremes in meteorological conditions becoming more frequent as result of climate changes, our data do suggest that under the conditions of precipitation of rain significantly under average annual quantities, a root zone salinization of arable land might occur in some areas of Denmark due to flooding from the sea or marine aerosol transportation, and the impact on conventional agriculture might be significant in following years.

\section{ACKNOWLEDGMENT}

This study was co-funded by The European Union Development Fund of the North Sea Region and by the Danish Business Authority. Assistance in preparing the illustrations by Laila Dam and Margrethe Nielsen as well as editing the text by Stephen Valentine is appreciated.

\section{REFERENCES}

Barrett-Lennard, E.G. 2003. The interaction between waterlogging and salinity in higher plants: causes, consequences and implications. Plant and Soil 253: 35-54.

Barrett-Lennard, E.G. and Shabala, S.N. 2013. The waterlogging/salinity interaction in higher plants revisited - focusing on the hypoxia-induced disturbance to $\mathrm{K}^{+}$homeostasis. Functional Plant Biology 40: 872-882.

Christensen, L.S. 2019. Some structural aspects of food production, food retail markets and procurement in Denmark - implications for national strategies of the REFRAME approach.https://northsearegion.eu/media/8786/structural-aspects-of-food-productionin-denmark-v3.pdf

Christensen, L.S., Mortensen, S., Boetner, A. et al. 1993. Further evidence of long distance airborne transmission of Aujeszky's disease (pseudorabies) virus. The Veterinary Record 132: 317-321.

Christensen, L.S., Normann, P., Thykier-Nielsen. S. et al. 2005. Analysis of the epidemiological dynamics during the 1982-1983 epidemic of foot-and-mouth disease (FMD) in Denmark based on molecular high-resolution strain identification. Journal of General Virology 86: 2577-2584.

Daliakopoulos, I.N., Tsanis, I.K., Koutroulis, A. et al. 2016. The threat of soil salinity: a European scale review. Science of the Total Environment 573: 727-739. 
Danish Meteorological Institute 2020. Archives of meteorological data. https://www.dmi.dk/ vejrarkiv/

De Waegemaeker, J. 2019. SalFar framework on salinization processes. A comparison of salinization processes across the North Sea Region. A report by ILVO for the Interreg VB North Sea Region project Saline Farming (SalFar). https://www.researchgate.net/ publication/333356242_SalFar_framework_on_salinization_processes_A_ comparison_of_salinization_processes_across_the_North_Sea_Region

De Vos, A. 2018. Training video: How to take a soil sample and measure soil salinity. https:// northsearegion.eu/salfar/news/taking-soil-samples-and-measuring-salinity/

Hingston, F.J. and Gailitis, V. 1976. The geographic variation of salt precipitated over Western Australia. Australian Journal of Soil Research 14(3): 319-335.

Jørgensen, N.O. 2002. Origin of shallow saline groundwater on the Island of Læs $\varnothing$, Denmark. Chemical Geology 184. 359-370. 10.1016/S0009-2541(01)00392-8.

Manca, F., Capelli, G. and Tuccemiei. P. 2015. Sea salt aerosol groundwater salinization in the Litorale Romano Natural Reserve (Rome, Central Italy). Environmental Earth Science 73: 4179-4190.

Shahid, S.A., Zaman, M. and Heng, L. 2018. Soil Salinity: Historical Perspectives and a World overview of the Problem. In M. Zaman, S.A. Shahid and L. Heng (Eds.) Guideline for Salinity Assessment, Mitigation and Adaptation Using Nuclear and Related Techniques. Springer, Cham. doi: https://doi.org/10.1007/978-3-319-96190-3_2. 


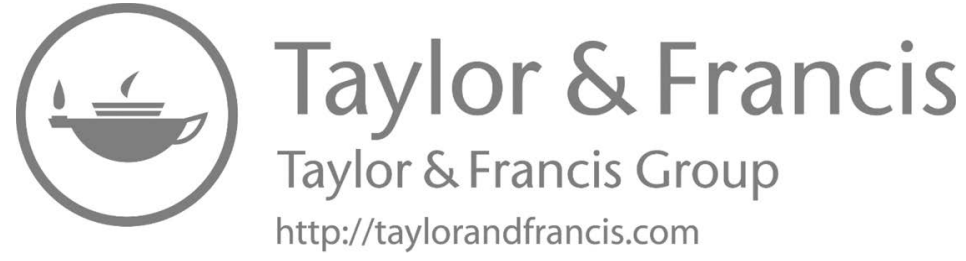

